\title{
Territorialidades de la acción estatal extraterritorial: burocracias diaspóricas y migrantes uruguayos en Nueva York y Buenos Aires
}

\author{
Territorialities of Extraterritorial State Action: \\ Diasporic Bureaucracies and Uruguayan Migrants \\ in New York and Buenos Aires
}

\author{
Silvina Merenson* \\ Conicet/CIS-IDES, Argentina
}

\section{$\overline{\text { RESUMEN }}$}

El artículo explora, mapea y conecta los lugares en los que la acción estatal extraterritorial es practicada por funcionarios consulares de Uruguay en Nueva York y Buenos Aires y mediada por los migrantes. En el marco de los estudios transnacionales, y a partir de un trabajo de campo multisituado, abordo la producción del espacio como lugar $y$, con ello, formas diversas de entender "el Estado", de representarlo o de sentirse representado por él. Para ello describo los lugares en los que la acción estatal extraterritorial cobra cuerpo. Las diferencias y semejanzas existentes entre los casos permiten advertir los modos en que las trayectorias migratorias, en su conjunción con "estilos consulares", territorializan (en el lugar de destino) políticas extraterritoriales (de origen).

Palabras clave: estudios transnacionales, burocracias diaspóricas, migrantes, territorialización.
DOI: https://doi.org/10.22380/2539472X.593

\begin{abstract}
$\overline{\text { ABSTRACT }}$
This paper explores and connects places where extraterritorial state action is practiced by officials of Uruguayan consulates in New York and Buenos Aires and mediated by migrants. In the framework of Transnational Studies, and based on a multi-situated fieldwork, I analyze the production of space as place, as well as diverse ways of understanding "the State", representing it or feeling represented by it. For that, I describe the places where extraterritorial state action takes shape. The differences and similarities between the cases allow us to observe the ways in which migratory trajectories, in conjunction with "consular styles", territorialize (at the place of destination) extraterritorial policies (of origin).
\end{abstract}

Keywords: Transnational Studies, diasporic bureaucracies, migrants, territorialization.

Doctora en Ciencias Sociales de la Universidad Nacional de General Sarmiento. Investigadora del Conicet y del CIS-IDES. Docente de la Universidad Nacional de San Martín. Su última publicación es Los peludos. Cultura, política y nación en los márgenes del Uruguay (Buenos Aires: Gorla, 2016). smerenson@unsam.edu.ar. 


\section{Introducción ${ }^{1}$}

En diciembre del 2016, en el Consulado uruguayo de Nueva York conocí a Marisa ${ }^{2}$, una ama de casa de 32 años, y a Federico, un camionero de 48 años. La pareja lleva más de una década viviendo en Estados Unidos y estaba allí para renovar sus pasaportes; habían aprovechado el día libre de Federico para hacer, en palabras de Marisa, “un paseo de novios” por Manhattan, ciudad que frecuentan muy raramente pese a vivir en Nueva Jersey, a unos quince minutos en tren. El trámite demoraba más de lo que pensaban. Un empleado del Consulado les dijo que los contactaría cuando estuviera listo, pero que podía tardar unas semanas. Marisa se desanimó un poco pero no demasiado: "y bueno, tendremos que venir otra vez", le dijo a Federico con cierto entusiasmo ante la posibilidad de un nuevo paseo. Al retirarse del Consulado me invitaron a caminar un rato con ellos. Marisa estaba ansiosa por ir al Rockefeller Center, pues quería fotografiarse junto al emblemático árbol de Navidad. Al llegar, acomodó su largo cabello negro y, pese al frío, se quitó el abrigo para colocar sobre sus hombros una chalina blanca. Mientras posaba como una verdadera modelo, buscó mi complicidad: “¿Viste? ¡Lástima que no tengo el pasaporte!”. Fue entonces que, con un gesto, me indicó que el blanco de la chalina y el azul de su remera componían la bandera uruguaya. Sin embargo, para ella, la "foto perfecta" la hubiese completado su pasaporte en mano.

En octubre del 2014, en plena campaña por las elecciones presidenciales que tendrían lugar en Uruguay a fin de mes, conocí a Graciela, una mujer de unos 45 años radicada en Argentina desde hace más de dos décadas. Graciela había llegado visiblemente angustiada a uno de los comités de base del Frente Amplio ${ }^{3}$ que funciona en el centro de Buenos Aires. Con la voz entrecortada contó a los militantes presentes que, por una

1 Una primera versión de este artículo fue presentada en el XVI Congreso de Antropología de Colombia y V Congreso de la Asociación Latinoamericana de Antropología realizados en Bogotá entre el 6 y el 9 de junio del 2017. Agradezco los comentarios realizados en dicha ocasión por los colegas con quienes compartí el simposio "Antropologías del estado en América Latina: convergencias, contrastes y paradojas"; así como a Federico Rodrigo, Matías Gimenez Constanzi, Rodrigo López Gadano y a los evaluadores anónimos de esta versión quienes, desde ya, no son responsables de los errores que puedan hallarse aquí. Vale finalmente mencionar que el uso genérico del masculino es política editorial de la RCA (que se rige por las normas de la RAE), no de la autora.

2 A fin de preservar el anonimato, los nombres de lugares, personas y asociaciones no corresponden en ningún caso a los reales.

3 El Frente Amplio (FA) es una coalición de izquierda fundada en 1971. Gobierna Uruguay desde que llegó a la Presidencia en el 2004. Comité de base es la denominación que reciben las células barriales del FA, integrados tanto por militantes de las fuerzas políticas como por 
vecina, supo que el Consulado iba a atender a los compatriotas en la ciudad del oeste del conurbano bonaerense en la que ella reside, que fue allí y escuchó que el Frente Amplio estaba "dando pasajes para viajar [en barco] a Montevideo, por las elecciones”. "Mirá lo que fui a hacer", dijo mostrando un certificado emitido por el Consulado en el que consta que no percibe ningún tipo de ayuda económica del Estado uruguayo: "soy enfermera, no tengo trabajo”. Graciela se había acercado al "Consulado itinerante" para tramitar aquel certificado, a fin de solicitar alguno de los planes de asistencia social del Estado argentino. Pero ese mismo paso consular fue el que la animó a dirigirse hacia el comité para preguntar si podían darle un pasaje que le permitiera ir a Montevideo a visitar a su padre, al que hacía más de seis años que no veía. Graciela no cumplía los requisitos para viajar a votar, ya que su credencial cívica estaba vencida. Los militantes le explicaron entonces que los pasajes no eran gratuitos, sino que se otorgaban a precios más económicos que lo habitual y que estaban destinados a quienes podían sufragar. Aun así, anotaron sus datos para contactarla. Llegado el día previo a las elecciones, la encontré nuevamente en la terminal portuaria, lista para embarcar a Uruguay.

A modo de viñetas, estas escenas registradas a lo largo de mi trabajo de campo indican modos distintos en que las personas migrantes incorporan a sus vidas sus pasos por las delegaciones consulares de sus países de origen y se relacionan - de formas tan creativas como imprevistas- con los documentos que estas emiten. Un trámite consular puede ser parte de un “paseo de novios” excepcional por una ciudad que, como veremos, resulta hostil, así como un pasaporte puede certificar la ciudadanía vivida (Pascucci 2016) en un lugar que no es un aeropuerto o un paso fronterizo. Una visita al Consulado y un certificado de ingresos también pueden ser parte de una serie de largos trámites en oficinas públicas ante la angustia del desempleo y, al mismo tiempo, una vía de acceso a una red política transnacional. En cada caso, las articulaciones entre las historias migratorias, las trayectorias profesionales de los funcionarios y los “estilos consulares”, así como las políticas de los países de destino (entendidas en un sentido amplio, no solo hacia la población migrante), producen territorialidades que revelan, entre otras cuestiones, formas diversas de entender "el Estado", de representarlo o de sentirse representado por él fuera de sus fronteras territoriales. En esta tarea, la diplomacia definida como una suerte de fuerza social que ocurre en distintos escenarios (Neumann 2013), y los documentos públicos, entendidos no como meras

militantes independientes, y su característica es el trabajo político y social en el territorio. Actualmente, en Buenos Aires, funcionan cerca de veinte comités de base. 
abstracciones sino como el Estado en acción (Peirano 2002), resultan cruciales, aunque, como veremos, no son las únicas materialidades que los involucran.

Este texto explora, mapea y conecta los lugares en los que la acción estatal extraterritorial es practicada y mediada por migrantes y funcionarios de los consulados de Uruguay en las ciudades de Nueva York y Buenos Aires. Se trata de países, ciudades, migraciones y “estilos consulares” diferentes entre sí. Son las diferencias, pero también las similitudes, las que nos interesarán aquí, a fin de reflexionar sobre algunos aspectos poco explorados de las experiencias transnacionales. Para ello, el texto que sigue se divide en cinco acápites. En el primero presento los principales aportes teóricos que, desde el campo de los estudios transnacionales (ET), reflexionan sobre la producción del espacio asociada a los flujos migratorios y reseño el trabajo de campo desarrollado. El segundo acápite sintetiza las principales características de la migración uruguaya, así como las trayectorias profesionales de las cónsules en Nueva York y Buenos Aires. En los acápites tercero y cuarto identifico y describo las territorialidades que resultan de las interacciones entre las delegaciones consulares y los migrantes en ambas ciudades. Las palabras finales conceptualizan y sintetizan algunas de las cuestiones derivadas de los datos etnográficos.

\section{Puntos de partida teóricos y metodológicos}

La problematización del espacio es un tópico central en los ET. Los debates acerca de la desterritorialización del Estado-nación (Basch, Glick Schiller y Szanton Blanc 1994), la producción de espacios sociales transnacionales (Faist 2004) o las experiencias urbanas de los transmigrantes (Besserer y Oliver 2014) son algunos ejemplos de ello. Como señalan Collyer y King (2015), los ET, tributarios del spatial turn (giro espacial) de los años ochenta, nutrieron un nuevo modo de pensar el espacio que puso en cuestión lo que hasta entonces era una concepción fija, anclada y dividida en Estados-nación mutuamente excluyentes. Como es sabido, la crítica a esta concepción y a uno de sus correlatos más evidentes —el "nacionalismo metodológico”- fue parte del programa fundacional de los ET.

El foco analítico puesto en los flujos, es decir, en aquello que se desplaza a través de fronteras locales, regionales y nacionales (capitales, mercancías, ideas, mensajes, objetos, personas, etc.), impulsó distintas reflexiones acerca de los modos en que el espacio es construido y opera como un principio organizativo de la vida social (Gupta y Ferguson 2008). Autores como Hannerz (1996) enfatizaron 
el papel de la vida cotidiana y las prácticas cara-a-cara como instancias en las que se generan los compromisos y las interpretaciones que producen el espacio. Para otros como Pries (1998), si bien el espacio remite a una serie de elementos intersubjetivos, no puede considerarse pura representación o metáfora, también es una realidad material e institucional. Dicho de otro modo: las relaciones sociales configuran diversas redes y conexiones que se constituyen -y son constituidas-a través de sitios materiales y lugares concretos (Featherstone, Phillips y Waters 2007). De ahí que recientemente la migración transnacional haya comenzado a ser estudiada a partir de sus materialidades y prácticas de lugar.

Sin embargo, en el campo de los ET, el acento puesto en estas cuestiones no siempre considera el rol de las políticas y prácticas estatales extraterritoriales -encarnadas en sus agentes más obvios y visibles, es decir, en los cuerpos diplomáticos- en la coproducción de los procesos por los cuales, en palabras de Gupta y Ferguson (2008), "un espacio adquiere una identidad específica como lugar”. Por lo general, cuando la literatura considera la acción de estas burocracias diaspóricas (Smith 2008) lo hace para ponderar los esfuerzos tendientes a captar las lealtades de los connacionales en el exterior o para analizar las respuestas brindadas ante la demanda de derechos por parte de los migrantes (Bauböck 2003; Hallet y Baker Cristales 2010; Lafleur 2012, entre otros). Así, al pensar en los migrantes como contribuyentes o gobernados, las relaciones entre estos y los cuerpos diplomáticos reproducen extramuros las expectativas recíprocas y las relaciones jerárquicas de poder existentes entre funcionarios estatales y ciudadanos intramuros, omitiendo que estas interacciones tienen lugar en otro espacio y contexto, fuertemente condicionado por el país de destino.

Fuera de las fronteras territoriales, los efectos del Estado descritos por Trouillot $(2003,151)$ parecen intersectarse y solaparse de maneras específicas, dando lugar a lo que entendemos aquí por territorialidades. A modo de ejemplo, el efecto de espacialización - definido en este caso por el país de destino-crea un efecto de legibilidad que se articula en el lenguaje, las clasificaciones y regulaciones con que opera la burocracia diaspórica sobre la población que administra y, de algún modo, gobierna. Estas atribuciones no se establecen unidireccionalmente, son más bien el resultado de distintas negociaciones y disputas con las personas migrantes, sobre las que a su vez se imprime el efecto de legibilidad del país de destino, tal como puede desprenderse de las descripciones que dan inicio a este texto. Esto último no es un dato menor pues, entre otras cuestiones, muestra los modos en que la racionalidad instrumental atribuida a las burocracias no solo es parte de una negociación compleja, sino que implica el rediseño de las políticas y prácticas de un Estado en el seno de otro a partir de saberes expertos, pero también del sentido común, los intereses políticos y las emociones en juego. 
Recientemente, distintas etnografías del Estado - me refiero, por ejemplo, a los artículos reunidos por Laszczkowski y Reeves (2015) - demostraron que las burocracias estatales, lejos del ideal weberiano, operan mediante la producción y circulación de emociones como el temor, el orgullo, la esperanza o la sospecha. Los afectos, para parafrasear a Weber, no solo son parte de las batallas cotidianas dirigidas desde los escritorios; también configuran los modos en los que se reproduce y transforma el Estado. Esta última constatación, sin embargo, resulta parcialmente cierta si no tomamos en cuenta que dichas emociones son producto de distintas y variadas interacciones. Los agentes estatales - aquí, los funcionarios consulares - no sienten en soledad, sino en relación con aquellas experiencias y emociones que expresan los migrantes y referentes de las comunidades en cuestión. Sin duda se trata de posiciones de poder y relaciones desiguales entre unos y otros, pero no por ello son menos significativas, ya que el modo en que circulan y se distribuyen territorialmente explica, al menos en parte, los vínculos entre norma y discrecionalidad.

Siguiendo a Hull (2003, 2012), aquí tomo la gestión y administración de documentos por parte de la burocracia diaspórica como mediaciones que organizan la vida de las personas, pero también la vida de las instituciones. La emisión de documentación, quizás la tarea más conocida, frecuente y rutinaria de los consulados, es más que una tecnología de control que permite la gobernabilidad de la diáspora. Los documentos vinculan personas, lugares, cosas, tiempos, normas y formas de sociabilidad de acuerdo con distintos patrones de interacciones (Hull 2012, 255). En parte, es en el marco de estas interacciones que se juegan y negocian las territorialidades de la acción estatal extraterritorial abordadas en este artículo.

Aún son escasas las investigaciones que se han detenido en las dinámicas y prácticas de los cuerpos consulares y sus relaciones con los migrantes. Entre ellos, el estudio de Dickinson (2015) sobre las articulaciones y colaboraciones entre las asociaciones de migrantes y el personal del Consulado General de la India en Sudáfrica destaca la importancia de conceptualizar a los consulados "no solo como oficinas administrativas para la administración extraterritorial de la población” (8, traducción propia). Su trabajo muestra el modo en que el Consulado de la India en Durban "es un lugar desde el cual una amplia gama de espacios mundanos y cotidianos, como salas de conciertos, templos, locales de música, academias de baile y antiguos hogares, se convierten en sitios para la diplomacia pública” (88, traducción propia). Esta transformación de "sitios ordinarios” en "sitios diplomáticos”, y viceversa, define, en términos de Dickinson, una serie de lugares interconectados en los que se expresan y negocian las subjetividades 
diaspóricas, pero también el éxito o el fracaso de los objetivos geopolíticos fijados por el Gobierno de la India. En una dirección semejante, Rodrigo (2017) analizó el rol del Viceconsulado boliviano en la ciudad argentina de La Plata en los procesos de etnización de los migrantes. Concretamente, los conflictos y resistencias que este debe enfrentar en los intentos de consolidar sus posicionamientos y construir su capital estatal en el marco de la denominada "diplomacia de los pueblos”, la doctrina inaugurada por el gobierno de Evo Morales en el 2013.

Si bien desde 1963 la Convención de Viena sobre las Relaciones Consulares establece, entre otras cuestiones, las funciones, competencias e inmunidades que caben a los cónsules, las políticas de atención y vinculación con la ciudadanía en el exterior son diseñadas por los Estados, tal como puede desprenderse de los trabajos citados. Para Uruguay, Aldaba (2017) registra las transformaciones en la política de vinculación del Estado para el primer gobierno del Frente Amplio (2004). De acuerdo con el autor, a partir de entonces el país abandonó los criterios restrictivos que dominaron tras la recuperación de la democracia (1985) para avanzar en un diseño institucional "en clave de 'reparación' de derechos para el ejercicio de la ciudadanía desterritorializada” (Aldaba 2017, 38). Esto implicó, además de un cambio en la estructura presupuestal del Estado ${ }^{4}$, una modificación del organigrama ministerial —en el 2005 se creó la Dirección General de Servicios Consulares y Vinculación en la Dirección General del Ministerio de Relaciones Exteriores - y la creación del programa Departamento 20, en cuyo marco se establecieron los Consejos Consultivos de Uruguayos en el Exterior (CC). Los CC fueron ideados como instancias de participación ciudadana en estrecha vinculación con los consulados. Si bien sus agendas varían de país a país, funcionan como apoyos institucionales - e instancias de escrutinio- de las delegaciones y gestiones consulares (Merenson 2015b). También, desde su creación, los CC fueron activos promotores del derecho al voto extraterritorial ${ }^{5}$.

El material empírico en que se basa este artículo es producto de una investigación etnográfica multisituada que desarrollé entre los años 2009 y 2015 en Buenos Aires, y entre noviembre del 2016 y mayo del 2017 en Nueva York. Siguiendo la propuesta de Marcus (1995), el trabajo de campo abarcó la interacción gundo tomo la planificación del desarrollo de la política de vinculación, lo que fue un hecho sin precedentes en esta materia" (38-39).

5 Vale señalar que Uruguay no cuenta con un mecanismo que permita el voto desde el exterior, aun cuando el voto es obligatorio. La Constitución nacional no suspende la ciudadanía y, por ende, los residentes en el extranjero conservan su derecho al voto. Quienes viven fuera del país pueden sufragar siempre y cuando se encuentren en el territorio nacional el día del acto electoral y estén inscritos en el Registro Cívico. 
con migrantes uruguayos que sostienen o sostuvieron en algún momento de sus trayectorias vitales prácticas transnacionales. Se trata de hombres y mujeres que llegaron a Buenos Aires o a Nueva York en diferentes periodos, pertenecientes a distintas clases sociales, que detentan diversos estatus migratorios. También incluyó la comunicación con funcionarios de las delegaciones consulares en ambas ciudades, tanto en el ámbito consular como fuera de él. Además de las incontables interacciones y conversaciones informales, el artículo se basa en más de cincuenta entrevistas en profundidad y treinta historias de vida, pero fundamentalmente recupera la observación y el registro etnográfico de las múltiples instancias públicas y semipúblicas de reunión de los migrantes -integrados o no a organizaciones de migrantes - con funcionarios y diplomáticos en Nueva York, Buenos Aires y Montevideo.

\section{Historias migratorias, trayectorias profesionales}

Las historias y las características de la migración uruguaya en Buenos Aires y Nueva York difieren entre sí. La primera es una migración limítrofe entre países del sur, que se remonta al periodo de conformación de los Estados nacionales en el siglo XIX y reconoce coyunturas críticas a lo largo del siglo XX. La segunda es una migración sur-norte que, aunque tiene antecedentes en la década de los sesenta, es mucho más reciente y pequeña en comparación con la anterior. Esta última se consolidó a partir de la ola de emigración desatada tras la crisis económica uruguaya del 2002. Según el último informe elaborado por la OIM (2011), los uruguayos residentes en Estados Unidos alcanzan un total de 56.884 personas, dos veces más que una década atrás. Casi el $45 \%$ de ellos se aglutina en los distritos de Nueva York y Nueva Jersey. En tanto, la mayor parte de los inmigrantes que componen la “diáspora uruguaya” (Merenson 2015b) suma 116.592 personas que están concentradas, en particular, en Buenos Aires y su región metropolitana.

La literatura sobre migración uruguaya en Argentina coincide en señalar que, desde sus orígenes, los uruguayos se incorporaron al país de destino de un modo particular y como ningún otro grupo migratorio de la región. Entre las razones de esta situación se suele apuntar el origen urbano de los migrantes, “con niveles educativos y una inserción ocupacional similar al promedio de la población nativa de la Argentina” (Benencia 2007, 588). Así, la similitud sociocultural (Recalde 2002) o la integración de hecho en virtud de la permanente interacción 
poblacional entre ambos países (Bertoncello 2001) serían algunas de las características que distinguirían esta migración.

En lo que respecta a la migración uruguaya en Estados Unidos, la literatura es aún más acotada. Posiblemente esto se deba tanto al carácter reciente como a la magnitud de esta migración, si se la compara con otros colectivos latinoamericanos en aquel país. El trabajo de Trigo (2003), que combina una serie de ensayos y testimonios recogidos en una comunidad de uruguayos en Massachusetts, introduce algunas cuestiones clave para nuestro análisis. Entre ellas, el modo en que los migrantes reproducen en el lugar de destino las segmentaciones sociales y culturales que privilegiaban en el Uruguay; también la voluntad reterritorializadora que detentan en tanto sujetos periféricos y subalternos en el país de destino.

A grandes rasgos, estas serían las características de la población migrante que reciben - “atienden”- los consulados en Buenos Aires y Nueva York, cuyas diferencias comienzan a percibirse desde el momento en que se ingresa en sus instalaciones. Hasta hace poco tiempo, el Consulado en Buenos Aires funcionaba en un gran edificio propio que compartía con la embajada, situado en el selecto barrio de Recoleta ${ }^{6}$. Por su parte, el Consulado en Nueva York funciona en un piso de un edificio situado en la avenida Madison, a pocas cuadras del Rockefeller Center. La composición de las delegaciones varía ${ }^{7}$ y tiene como empleados administrativos a uruguayos radicados en las respectivas ciudades.

Laura es cónsul en Buenos Aires y es lo que, en la jerga estatal, se conoce como una "funcionaria política”. En tanto Mónica — su colega en Nueva York—es "funcionaria de carrera”. Sus trayectorias biográficas y profesionales son muy diferentes y, en consecuencia, también lo son sus estilos de gestión consular. Laura, que migró a Buenos Aires en 1974, fue designada en su cargo tras el arribo de José Mujica a la Presidencia (2010). Su nombramiento, dice, fue parte del reconocimiento a su extensa labor en el Frente Amplio de Uruguay en Argentina (FAUA), aquel que integra desde su fundación en los primeros años de la década de los ochenta. En su persona, el Gobierno buscó reconocer el compromiso político de "los uruguayos en Argentina”, sintetizado paradigmáticamente en su participación electoral transnacional. Mónica, en tanto, llegó al Consulado en Nueva York como parte de la rotación de los diplomáticos en el exterior y todo su recorrido profesional se ajusta al campo de la diplomacia.

Actualmente lo hace en una antigua casona, en la misma zona porteña. Mi trabajo de campo transcurrió en los tiempos de su sede anterior.

7 Durante mi trabajo de campo, en Buenos Aires el cuerpo consular estaba integrado por un cónsul general y tres cónsules de distrito; en Nueva York, por un cónsul general, un cónsul de distrito y un cónsul adjunto. 
Por sus disímiles trayectorias biográficas y profesionales, la socialización de ambas en la diáspora de sus respectivas jurisdicciones también es distinta. Mientras Laura es parte de ella desde hace más de cuarenta años - por lo cual conoce ampliamente el complejo mapa de sus asociaciones y organizaciones sociales y políticas - , en el caso de Mónica, este tipo de saber es parte de un aprendizaje en curso. Como veremos, en cada caso la proximidad o distancia respecto de "los compatriotas" asume distintas traducciones. Si Laura debe administrar las relaciones políticas — que en ocasiones tensan su investidura-, cuyas funciones y reglas de etiqueta aprendió “sobre la marcha”, Mónica -que es interpretada solo a partir de su cargo diplomático - enfrenta una serie de dificultades para "acercar a la gente al Consulado" cuando este organiza alguna actividad. Sin embargo, su perfil “técnico” le permite orientar y resolver con fluidez muchas de las consultas que recibe diariamente en su oficina.

Los modos en que cada una encarna y representa al "Estado uruguayo" y se vincula con los migrantes varían según sus trayectorias profesionales, las características de la migración uruguaya en cada jurisdicción y las políticas de los países y ciudades de destino. Asimismo, varían los modos en que estas representaciones se practican y territorializan.

\section{Territorialidades de la acción estatal extraterritorial en Nueva York}

Durante nuestro primer encuentro, Mónica sintetizó lo que llamó “el mapa de los uruguayos en Nueva York”. Dicho mapa combina la coyuntura de arribo al país, la pertenencia de clase y el lugar de asentamiento. Explicó que existe un grupo de profesionales y directivos de empresas llegados en las décadas de los sesenta y setenta, que vive mayoritariamente en Brooklyn y está "completamente integrado, sus hijos son norteamericanos” y, en algunos casos, “también sus parejas”. A este perfil responden quienes integran Casa Oriental, una de las dos fundaciones de ayuda y colaboración con el Uruguay que existen en Nueva York, que cuenta ya con veinte años de historia. La otra, HU, es una organización social transnacional que tiene dos voluntarias en esta ciudad: dos mujeres pertenecientes a la 
élite montevideana, radicadas en Manhattan, en donde trabajan como ejecutivas de un estudio jurídico y contable ${ }^{8}$.

"Este grupo”, explicaba Mónica, "no necesita mucho al Consulado”. De este modo se refería a una de las funciones consulares, quizá la más conocida o habitual: la gestión de documentos, es decir, de partidas de nacimiento, matrimonio o defunción, pasaportes, certificados de existencia y poderes notariales, entre otros. Dado que los integrantes de este grupo viajan regularmente a Uruguay, muchos de estos trámites los realizan en el país. Esta es una opción que también sigue la media de los uruguayos en Buenos Aires, que suelen visitar Uruguay muy frecuentemente, dada la corta distancia, los costos accesibles del viaje y el estatus migratorio alcanzado.

Los vínculos de Mónica con quienes integran este grupo tienen lugar durante las actividades sociales a las que es convocada por su cargo: ya sean los picnics en parques celebrados por Casa Oriental los 25 de agosto (fecha de la Independencia uruguaya), los eventos para recaudar fondos destinados a distintas instituciones públicas uruguayas o las "galas" anuales de HU, organizadas en algún hotel de Manhattan. Se trata de espacios y prácticas de lugar distintas: en los eventos públicos y abiertos de Casa Oriental, lo que prima es la acción solidaria entre "compatriotas", pues los principales benefactores son los migrantes. En el caso de las galas de HU, eventos cerrados y restringidos, los benefactores no son connacionales sino integrantes del establishment neoyorkino, quienes pagan costosas entradas y, durante la velada, participan en subastas de obras de arte cuyas cargas deducen del pago de sus impuestos, de acuerdo con la ley tributaria estadounidense. Si bien ambas fundaciones orientan su acción hacia Uruguay, se trata de "eventos" que suponen espacios y presencias institucionales diferentes. Mientras aquellos protagonizados por la comunidad son instancias de encuentro informales desarrolladas en sitios públicos (parques, plazas), en los que la presencia consular encarnada por Mónica es una oportunidad para "escuchar las necesidades de los compatriotas", en el caso de las galas la presencia consular es protocolar: "estás allí para transmitir el agradecimiento en nombre del Estado".

El "polo opuesto" de este primer grupo está conformado por quienes en su mayoría llegaron a Estados Unidos tras la crisis del 2002. Según la descripción de Mónica, este segundo grupo estaría integrado por trabajadores calificados y sin calificación, pertenecientes a los sectores populares o las clases medias

Una de ellas, Lucrecia, tiene 39 años y llegó a Nueva York en el 2008 para realizar un posgrado. Luego de concluirlo, junto a su marido y sus dos hijos, decidieron quedarse a trabajar por un tiempo en la ciudad. La segunda integrante de HU, Eugenia, tiene 32 años y llegó en el 2012. De niña había vivido en la ciudad, pues su padre es diplomático y Nueva York fue uno de sus múltiples destinos. 
uruguayas, que actualmente suman más de 7.500 hombres y mujeres uruguayos, asentados predominantemente en ciudades de Nueva Jersey, como Elizabeth y Newark. Ambas, explica Mónica, son “ciudades bastante pobres”, en las que "hay muchos migrantes, porque Manhattan tiene costos imposibles”. Pero, en rigor, esta no es la única razón por la cual "los compatriotas" se asientan en ellas: según me explicaban, la escala de estas ciudades resulta más amigable, su sistema de asistencia social - especialmente a la infancia- es mejor que el que ofrece Nueva York y, en ellas, se sienten menos expuestos a las razias policiales. Esto último es algo que a Mónica le resulta difícil de comprender: “Manhattan”, dice, “es mucho más seguro. El alcalde de Elizabeth lleva veinte años en el cargo, conoce a todos. Si un día quiere denunciar 'ilegales', lo hace en un segundo”. Su lectura, sin embargo, no considera aquello que escuché reiteradamente entre los uruguayos en Nueva Jersey, sobre cierto "pacto de tolerancia” entre las autoridades y los habitantes de la ciudad, documentados y no. A modo de humorada, mientras compartíamos un café y unos bizcochos en la “bakery uruguaya” de Elizabeth, un veinteañero nacido en Montevideo decía: "si cae Migraciones acá, esta ciudad se queda sin gente”.

El temor a la deportación no es la única razón por la cual "los compatriotas” de este segundo grupo identificado por Mónica evitan Manhattan. Recorrer esta ciudad, para muchos, supone saberes que no tienen o una serie de riesgos que atribuyen a su trajín diario. Son variadas las experiencias a la hora de explicar las razones por las cuales pueden pasar largos periodos "sin pisar la isla": Mario, un tornero de 53 años nacido en Tacuarembó, que llegó a Estados Unidos en el 2003, explicaba que no sabe "andar en subway”. Alejandra, que con 32 años pasó más de la mitad de su vida residiendo entre Newark y Elizabeth, contó que perdió de vista por unos minutos a su hija en la congestionada Times Square, y que su angustia fue tal que, desde aquel evento ocurrido hace 4 años, no regresó a la ciudad. Elsa, un ama de casa de 48 años asentada en Newark hace 14, decía que no encuentra motivos "para ir hasta allá, porque aquí tienes todo: tiendas, el mall, la bakery”. Su enumeración resume con bastante precisión los lugares que concentran la atención de los uruguayos en Nueva Jersey, especialmente durante los fines de semana. En buena medida, estos circuitos de consumo y sociabilidad situados en Newark y Elizabeth desdibujan la condición de clase y la condición de migrante que Manhattan, por el contrario, parece exponer. En consonancia con esta impresión, según decía uno de los empleados administrativos del Consulado, “ellos, allá [en Nueva Jersey], armaron como su mundo aparte”.

Las experiencias asociadas a Manhattan antes reseñadas entorpecen las interacciones de este grupo con el Consulado y, en parte, explican la afirmación 
de Mónica: “aquí vienen cuando necesitan algo” y no, por ejemplo, cuando el Consulado organiza alguna actividad cultural. Esta distancia simbólica, que se imprime sobre la distancia física (Evans-Pritchard 1977), también se refuerza con la decisión institucional de no realizar trámites por vía telefónica, cuestión que explican por la falta de personal, pero especialmente por la necesidad de evitar "gestores" - intermediarios - que se beneficien con los trámites consulares. Esto último, que también es una preocupación en el Consulado en Buenos Aires, adquiere mayor peso en el caso de Nueva York, ya que son frecuentes las estafas a quienes buscan obtener la residencia legal en el país. Aunque estas limitaciones intentan compensarse con la realización de “consulados itinerantes”, estos suelen abarcar otros estados de la jurisdicción.

Vale señalar que, por lo general, las jurisdicciones consulares cubren territorios muy extensos del país de destino. Es habitual entonces que sus agentes se desplacen por distintas ciudades para cumplir con su función de documentación, promoción y divulgación, siempre dentro de su jurisdicción y condicionados por el presupuesto asignado (Kishan 2007). Se trata de instancias clave para los propósitos de este artículo, en tanto la acción consular abandona su espacio habitual - en el que rige la normativa del país que representa-para funcionar, tal como veremos, en las más variadas instituciones estatales y organizaciones de la sociedad civil del país de destino. Los consulados itinerantes, en una de sus dimensiones centrales - la documentación-, son un buen ejemplo del modo en que “los papeles” vinculan personas, lugares, normas y formas de sociabilidad, territorializando de modos diversos la acción estatal extraterritorial.

A los parques y hoteles en donde se territorializa la acción estatal consular que mencionamos hasta aquí, mis interlocutores en Nueva Jersey sumaban el Club Unidos. Creado en el 2010, el club cuenta con un local a pocas cuadras de la estación de tren de Elizabeth. En él tienen lugar distintos festejos, así como shows de artistas llegados desde Uruguay a los que también asisten "hermanos de otras nacionalidades”, aunque mayoritariamente latinoamericanos. A diferencia de lo que sucede en Buenos Aires, la "latinoamericanización”9 de los uruguayos en Nueva Jersey ocurre mediante el mercado matrimonial y las relaciones de amistad y vecindad, vitales para esta colectividad, pequeña en números relativos y

9 Esta expresión requiere de un desarrollo mayor del que podemos formular aquí. Digamos brevemente que, desde la primera mitad del siglo XX y anclada en una serie de rasgos diacríticos, la matriz europeísta operó como distancia y distinción de Uruguay con respecto a América Latina. La narrativa nacional del país como "la Suiza de América", que permeó y se sedimentó en amplios sectores de la sociedad uruguaya más allá de sus crisis y revisiones (Espeche 2016), es para los migrantes uruguayos en Estados Unidos una experiencia masiva que los confronta cotidianamente con las fugas de tal narrativa. 
comparativos. Sin embargo, esta identificación estratégica - pero no por ello menos vívida- no es exclusiva de los migrantes; también el cuerpo consular apela a ella a fin de fortalecer su poder de negociación ante distintas instituciones públicas y privadas locales de su jurisdicción. Tal es el objetivo de la Coalición de Cónsules Latinoamericanos en Nueva York (Clacny), que reúne a funcionarios de diecisiete países del continente, Uruguay entre ellos ${ }^{10}$.

El club, según explicaba Antonio, uno de sus fundadores, busca "juntar a los uruguayos que andamos en la vuelta, para mantener nuestras costumbres y hablar de nuestras cosas”. Su objetivo no es la acción filantrópica hacia el Uruguay, sino más bien la promoción de espacios que hagan más llevadera la distancia. Plagado de imágenes y objetos nacionales, el club es un lugar íntimo en el que se juega, baila y canta lo que se entiende como propio y se desea compartir con otros. Pero no es pura nostalgia aquello que motoriza este lugar; allí también se resuelven muchos problemas cotidianos asociados a la migración. Cuando estos exceden la red de amistad y vecindad, "se avisa al Consulado". Se trata de situaciones que exponen criterios - a veces diferenciales - respecto de cuándo un evento puede ser considerado un "problema" que demanda la intervención del Consulado, de los referentes de la comunidad migrante o de ambos. También son instancias en las que los funcionarios diplomáticos quedan sujetos al escrutinio de la comunidad, como sucede por ejemplo con la decisión sobre una repatriación o el comportamiento ante una deportación.

Para el 2016, en los tres años que llevaba en su cargo, Mónica debió ocuparse de un solo caso de "repatriación”: el de una mujer víctima de violencia de género. Según Mónica, la repatriación de una persona es "una de las decisiones más complejas de tomar para un cónsul”. En este caso, recordaba con gran tristeza,

[...] hablé mucho con ella y con sus amigos, y llegamos a la conclusión de que iba a estar mejor allá que acá. Pero no es fácil, vos estás decidiendo algo importantísimo, porque a Estados Unidos ya no entra más: no legalmente. Sos vos la que da curso a la solicitud.

En este caso, el club albergó el proceso de repatriación decidido por el Consulado en acuerdo con la mujer.

En cuanto a las deportaciones, que para la jurisdicción del Consulado uruguayo en Nueva York involucraban unas veinte anuales entre el 2014 y el 2016, lo que prima en la forma de entender de Mónica es el deslinde personal de la

10 Creada en el 2008, la Clacny promueve cursos de capacitación y acuerdos con empresarios y políticos locales sobre acceso a la justicia, salud, trabajo y educación de la comunidad latina. Según definía Mónica, para el caso de las "comunidades pequeñas como la nuestra", esta instancia "resulta muy útil". 
responsabilidad del Estado que representa, pero también cierta sensación de injusticia e impotencia ${ }^{11}$. Según afirmaba, "la mayoría de las deportaciones de uruguayos se dan por infracciones muy tontas: los agarran por exceso de velocidad, por alguna borrachera. No son cuestiones pesadas”. En sus palabras, en estos casos los límites de la injerencia consular quedan claros en la apelación a una serie de saberes y competencias específicas que muestran inviable su acción administrativa. Como lo señalaba, “a mí me avisan de una deportación y... yo no soy abogada, ni soy policía. El uruguayo en Estados Unidos está sujeto a las leyes migratorias de Estados Unidos. A veces no se entiende que desde el Consulado no se puede hacer nada”. Esta última frase alude, elípticamente, a las críticas que pude escuchar entre los migrantes, quienes conocen las políticas migratorias estadounidenses pero no necesariamente saben cuáles son los límites de la acción consular y esperan un mayor desempeño por parte de los funcionarios. Desde sus perspectivas, la ayuda ante la deportación de "un compatriota” parece recaer en la comunidad que se moviliza para recaudar fondos que permitan sostener a las familias de los detenidos y retornarlas a Uruguay o para visitarlos en los centros de detención y conseguir asesoramiento legal. De ahí que Elsa, a quien citamos arriba, demandaba del Consulado: "que se mueva un poco, que vengan a ver qué pasa, que los vayan a visitar, que les consigan un abogado, que ayuden a su familia, ¿no?”, para luego quejarse, sosteniendo que "los políticos son todos iguales, vienen cuando necesitan algo”.

Las palabras de Elsa sintetizan algunas cuestiones clave para la presente discusión. Una de ellas es la identificación de quienes integran las burocracias diaspóricas como "políticos", al menos cuando estos no cumplen sus expectativas pero esperan el cumplimiento de las propias. En segundo término, la territorialización de esta suerte de reciprocidad quebrantada: Elsa y otros migrantes esperan que los funcionarios “se muevan” —que se desplacen hacia los centros de detención, que vayan a visitar a los familiares - si esperan que los migrantes también lo hagan; es decir, que también "se muevan” para acudir, por ejemplo, a las reuniones realizadas en ocasión de las visitas de las máximas autoridades nacionales, como el canciller o el propio presidente de la República en gira oficial. En estos casos, las visitas de las autoridades se transforman en instancias en las que los funcionarios exponen y buscan legitimar su labor, en consonancia con los objetivos fijados por el Gobierno en materia de vinculación y política exterior.

Además de estas interacciones, en las que las territorializaciones de las acciones estatales extraterritoriales muestran sus potencialidades pero también

11 De acuerdo con la normativa vigente de la Convención de Viena sobre Relaciones Consulares de 1963. Según esta norma, los cónsules no tienen potestad para frenar deportaciones ni pueden interponerse ante las políticas migratorias de los países en los que están destinados. 
sus límites, existen otras de carácter ritual, en las que el espacio público cobra particular relevancia: el acto conmemorativo del día de la Independencia uruguaya (25 de agosto) en la Alcaldía de Elizabeth, el Desfile Hispano en esta misma ciudad en septiembre y el tradicional desfile del Día de la Hispanidad en el mes de octubre en Manhattan.

En el primer caso, se trata de un acto que la Alcaldía de Elizabeth repite en las fechas nacionales de todos los países cuya población migrante es significativa en la ciudad. En cada una de estas fechas, en la escalinata del City Hall, se iza la bandera nacional junto a la estadounidense, se cantan ambos himnos nacionales y se hace un baile tradicional del país homenajeado. De este modo, el gobierno local celebra a cada colectividad visibilizando su contribución a la ciudad, pero también crea el espacio/tiempo para exponer su “drama social” (Turner 1974). En el 2009, en ocasión del festejo, Juan informó la detención de "un hermano" y convocó a recaudar fondos "para darle support a la familia”. Al año siguiente, Ignacio anunció la suspensión del baile tradicional, porque uno de los integrantes del cuerpo de danzas se encontraba detenido, esperando a ser deportado. Con la voz quebrada, pidió disculpas e informó de la apertura de una cuenta bancaria para juntar el dinero que les permitiera a su mujer y sus tres hijas retornar a Uruguay. Juan e Ignacio eran por entonces miembros activos del CC de Nueva York, Nueva Jersey y Connecticut.

A diferencia de la fecha patria celebrada por la Alcaldía de Elizabeth, los dos desfiles mencionados convocan una adscripción identitaria que excede a los uruguayos, pero a la que acceden particularmente mediante el candombe afrouruguayo. El desfile de las distintas cuerdas de tambores de este género musical, conformadas en las diferentes ciudades vecinas, los enlaza con el Atlántico negro (Gilroy 2014), pero también con las delegaciones consulares que comparten con ellas los desfiles. En estas fechas las ciudades son masivamente ocupadas por "lo latino" y, por efecto ritual, los temores hacia el espacio urbano al que me referí previamente parecen neutralizados, así como la distancia estructural y simbólica que media entre "los compatriotas” y las burocracias diaspóricas que vimos para otras situaciones. 


\section{Territorialidades de la acción estatal extraterritorial en Buenos Aires}

A diferencia del “mapa” bosquejado por la cónsul en Nueva York que, como veíamos, es el resultado de la combinación de la coyuntura de arribo a Estados Unidos, la pertenencia de clase y el lugar de asentamiento, el "mapa” que propone Laura, cónsul en Buenos Aires, está dominado por las identificaciones políticas. Ella se refería a quienes llegaron en los años de la dictadura (1973-1985) y a quienes llegaron a fines de los años ochenta y en los años noventa, que componen una migración cuya razón es “económica”. Sin embargo, esta primera clasificación es rápidamente matizada por el reconocimiento de "un ir y venir constante" entre ambos países desde tiempos remotos, que la lleva a afirmar que hoy "hay uruguayos por todos lados” y que esta dispersión, justamente, es una de las grandes dificultades de su trabajo: “es como buscar una aguja en un pajar”. Incluso, asegura que los uruguayos en Buenos Aires "son más de lo que dicen los censos, porque vos te encontrás gente que hace cuarenta, cincuenta años que vive acá, que hace años que está radicada y que, cuando les preguntan, dicen que son argentinos porque tienen DNI [documento nacional de identidad]. Nosotros calculamos que el número [de migrantes] siempre es más o menos el triple” del señalado por los censos.

La heterogeneidad y dispersión geográfica que mencionaba Laura tienen su correlato en la gran cantidad de organizaciones o instancias informales de reunión de la diáspora en Buenos Aires. Además de la red política del FAUA, sobre la que luego volveré, existe una serie de circuitos sociales, deportivos y culturales que conectan diferentes barrios porteños y ciudades del conurbano bonaerense con Montevideo o con ciudades intermedias uruguayas. El vínculo consular con estos espacios cobra especial relevancia durante los festejos del calendario nacional, fechas en las que sus artistas son convocados a participar en los espectáculos que siguen a los actos protocolares. En estas fechas, el amplio auditorio del Consulado se colmaba de “compatriotas” que compartían las actuaciones de cuerdas de tambores, murgas y cuerpos folclóricos de danza en un clima de verdadera fiesta. Son ocasiones en las que los funcionarios consulares informan -y en cierto modo plebiscitan- sus gestiones, especialmente cuando se trata de anunciar nuevos beneficios o “servicios” para la diáspora local.

A diferencia de lo observado en la jurisdicción del Consulado en Nueva York, actualmente no hay en Buenos Aires fundaciones que tengan por objetivo la ayuda filantrópica hacia Uruguay. Desde hace más de una década, la diferencia 
cambiaria a favor de Uruguay dificulta el envío de remesas materiales o monetarias. Como se verá, las remesas que llegan desde Buenos Aires no son de este tipo, sino políticas (Goldring 2004). Estas orientan parte del desempeño y esfuerzo consular.

Por su trayectoria, para Laura el equilibrio entre la militancia política y la función estatal suele ser difícil y, de hecho, es blanco de algunas críticas que apuntan hacia "la politización del Consulado" bajo su gestión; cuestión que a su vez encuentra contrapartida en quienes creen que "se volvió una burócrata” por no considerar en la atención sus relaciones políticas y personales preexistentes a su designación. Según Laura, su trayectoria es justamente la que le permite "estar cerca, saber lo que necesitan” los migrantes y "ser un consulado presente”: “el cónsul es como un médico”, afirmaba, "está para asistir al compatriota, sea quien sea, en cualquier momento". Esta última definición orienta su "estilo consular”, aquel que la sitúa en las antípodas de las gestiones que la precedieron: “acá [en Buenos Aires] los consulados fallaban, porque los cónsules llegaban y creían que todos los uruguayos vivían en Barrio Norte ${ }^{12}$. Claro, toda la gente que iba al Consulado era la de Barrio Norte, al uruguayo pobre que llegaba lo echaban en la puerta”. Así, por oposición a la imagen de un consulado circunscrito a una clase que se corresponde con una localización geográfica en la ciudad, Laura ubicaba su trabajo más allá de esta frontera, en consonancia con las nuevas políticas de vinculación del Estado uruguayo mencionadas en el segundo acápite: “yo salgo y lucho muchísimo contra la burocracia”.

Entre "las salidas" de Laura se encuentran las visitas a los penales donde hay población uruguaya, especialmente las cárceles de mujeres que, según explica, se hallan en situación de mayor vulnerabilidad y “están presas por pobres”. Cada vez que viajaba a Montevideo, Laura tenía por costumbre comprar distintos recuerdos (banderines de clubes de fútbol, símbolos nacionales) para llevarles de regalo. Vale mencionar que la legislación argentina estipula la expulsión de las personas extranjeras privadas de su libertad cuando estas cumplen la mitad de la condena. Entre el 2013 y el 2015, Argentina deportó a Uruguay unas 150 personas detenidas en distintas cárceles del país. En estos casos, el trabajo del Consulado consiste en emitir la documentación necesaria para que pueda concretarse el ingreso al país, tarea que Laura busca realizar sin dilaciones y con gran tristeza.

Mientras funcionó el CC en Buenos Aires (CCBA), en el marco del programa Departamento 20 referido, algunas de sus integrantes colaboraron con la asistencia a las uruguayas privadas de su libertad, recolectando ropa o escribiéndoles 
cartas. Estas tareas eran consideradas formas de "apoyar el trabajo de la cónsul”, tal como explicaba Blanca, quien vive en Buenos Aires hace más de treinta años y se sumó al CCBA luego de comprobar "el compromiso de [Laura] y su equipo de trabajo”. Estas deportaciones, vale aclararlo, no suponen los mismos sentimientos o reclamos de presencia consular y, mucho menos, el mismo grado de empatía de los uruguayos en Nueva Jersey. Entre quienes integraban el CCBA existía un amplio consenso respecto de la inapelabilidad de esta disposición argentina que consideran comprensible e incluso justa. "Serán uruguayos, pero son personas que cometieron un delito. Es lógico que Argentina los expulse”, decía Mirta, una traductora que reside en Buenos Aires desde 1986. En estos casos, ni la "necesidad" ni la "pobreza” de quienes son deportados resultan un justificativo o atenuante. Por el contrario, son casos que moralizan en términos ejemplares lo que se espera de la conducta de un migrante.

Desde que asumió su cargo, Laura se ocupó particularmente de fortalecer el CCBA. Para ello convocó a “compañeros” y “compatriotas” dispuestos a colaborar con el “trabajo social” desarrollado durante su gestión. Entre el 2011 y el 2014, el CCBA se mantuvo sumamente activo. Entre todas sus tareas, la más visible fue el lanzamiento de la Tarjeta Celeste, que ofrecía a los residentes uruguayos en la ciudad una serie de descuentos en diferentes rubros, incluidas distintas empresas de transporte a Uruguay. Sin embargo, su trabajo territorial, que tenía lugar en los ámbitos de reunión de la colectividad —fundamentalmente en plazas, ferias y negocios gastronómicos-, fue menguando hasta que, en el 2014, el CCBA se disolvió, producto del agotamiento y algunos conflictos entre sus integrantes, pero también por el inicio de la campaña electoral con vistas a las elecciones presidenciales de aquel año. En su gran mayoría, quienes integraban el CCBA decidieron concentrar sus energías en la campaña electoral del FA.

De todas las tareas que caben en su función, hay dos que Laura considera centrales: la “documentación” y la "repatriación”. Con respecto a la primera, su trabajo se ve incrementado y potenciado por las "pruebas piloto" sobre atención consular que la Cancillería uruguaya realiza en su jurisdicción. Tal es el caso del Operativo Celeste que, desde el 2005 y en sucesivas etapas, expidió miles de cédulas de identidad. Al inicio, este programa dio respuesta a los requisitos planteados por el programa estatal argentino Patria Grande, que promovió la regularización migratoria de los extranjeros nativos de los Estados parte del Mercosur y Estados Asociados ${ }^{13}$. También es el caso del plan piloto de implementación del pasaporte electromecánico, iniciado en el 2012 en el Consulado en Buenos Aires. 
Por lo general, los compatriotas que mayormente requieren del Consulado para tramitar su documentación pertenecen a los sectores populares. Dados la proximidad geográfica, los vínculos familiares y afectivos, y el costo de los traslados es muy habitual que los migrantes pertenecientes a las clases medias y altas realicen sus trámites durante alguna de sus frecuentes visitas al país, o que estos trámites sirvan de “excusa” para programar un viaje. En cambio, para los sectores populares, el Consulado suele ser la única opción cuando se trata de tramitar su “documentación uruguaya”, indispensable tanto para obtener la residencia como para acogerse a alguno de los programas estatales argentinos. "En estos últimos años”, explicaba Laura, “el Gobierno argentino implementó una serie de planes sociales. Entonces, gente que de repente antes no veía la necesidad de tener su documentación, vino a hacerla”. Tal es el caso de Graciela, a quien presentamos en la segunda viñeta que da inicio a este texto.

Dado que para estos compatriotas incluso es difícil llegar al Consulado -en tanto implica viajar varios kilómetros, costear pasajes o perder un día de trabajo-, Laura promueve activamente la realización de "consulados itinerantes” en distintas ciudades del conurbano bonaerense y de provincias bajo su jurisdicción. La definición de las ciudades y lugares en donde se instala un consulado itinerante combina distintos criterios que resultan trascendentes en la medida en que permiten comprender el modo en que las acciones de las delegaciones consulares se territorializan en el país de destino. Si bien estos criterios están basados en el presupuesto otorgado al Consulado para su funcionamiento y la demanda de atención por parte de "los compatriotas", también incide la relación del cuerpo consular con los gobiernos locales de las potenciales ciudades a visitar, así como la disponibilidad de un espacio adecuado para su funcionamiento. Este, idealmente, es la propia municipalidad. Vale señalar que, además de la vía consular, la difusión de las ciudades en las que se llevan a cabo los consulados itinerantes suele ser realizada por los propios municipios receptores $y$, en consecuencia, incorporada a los servicios otorgados a sus habitantes. Es entonces habitual que burocracias diaspóricas e intendentes locales "se ayuden mutuamente" en caso de tener "coincidencias políticas", tal como mencionaba uno de los empleados del Consulado en Buenos Aires. Así, el mapa de los consulados itinerantes en buena medida refleja - aunque no se limita a- las afinidades personales y las existentes entre el Gobierno nacional uruguayo y los gobiernos locales argentinos.

La segunda tarea que Laura considera clave de su “estilo consular” es la repatriación de personas. A diferencia de lo visto en Nueva York, las repatriaciones desde Buenos Aires son mucho más frecuentes por varias razones que incluyen 
la posibilidad de retorno a Argentina en virtud de sus políticas migratorias, pero también por los costos de traslado, cubiertos por el vínculo del Estado uruguayo con una de las empresas fluviales que unen Montevideo y Buenos Aires. Para Laura no median muchas dudas: la repatriación de personas se presenta como una tarea que no admite dilaciones burocráticas. Así lo ejemplificaba con el caso de "un pibe [joven] que estaba durmiendo en la calle” y llegó al Consulado cuando ya estaba por concluir el horario de atención consular. En esta ocasión, decía Laura evocando su indignación, "si el pibe se quedaba en la calle dos días más, terminaba preso. Le digo entonces a una empleada: 'conseguí un pasaje y mandalo' [a Montevideo]. Y me dice: 'pero hoy es viernes, no nos van a dar un pasaje'. ¿A vos te parece que a [la empresa] le puede importar un pasaje? ¡Lo que ella no quería era quedarse trabajando después de hora!”. Su respuesta a la empleada es indicativa de lo que entiende como compromisos sociales diferenciales, que en su caso se completa en su "lucha contra la burocracia”, evidenciada también en una interpretación flexible de las normativas vigentes a la hora de repatriar a una persona en más de una ocasión. En este sentido, sin ser una "funcionaria de carrera”, Laura despliega aquella "necesaria flexibilidad para lidiar con lo inesperado" (Kishan 2007, 122) que puede hallarse en los manuales de formación diplomática.

Como se mencionó, el vínculo más fuerte de Laura - y la base de su estilo consular - es con la militancia frenteamplista en el país. Sin embargo, desde que fue designada en su cargo muchas de las tareas que realizaba o los lugares que frecuentaba se tornaron formalmente incompatibles con su función. Laura, entonces, dejó de ser visible en las reuniones semanales del comité que ayudó a fundar y dejó de asistir a los diversos actos que tienen lugar en Buenos Aires en tiempos de campaña electoral, pero no por ello dejó de colaborar en las visitas de los distintos candidatos, o de cooperar en el establecimiento de vínculos entre estos y los dirigentes políticos argentinos. Esta última cuestión no solo es crucial en términos de las alianzas políticas transnacionales, también es vital a la hora de fortalecer y expandir la labor consular, pues de estos vínculos resultan acuerdos en beneficio de la diáspora uruguaya en el país ${ }^{14}$, así como la selección de lugares para llevar a cabo los consulados itinerantes.

En otros trabajos (Merenson 2013, 2016) he dado cuenta de los modos en que, ante la ausencia de un mecanismo que permita el voto extraterritorial, los uruguayos en Argentina se movilizan masivamente hacia Uruguay a fin de sufragar. De ahí que en tiempos de elecciones la labor consular se incremente, pues el buen o mal funcionamiento consular es uno de los criterios que define el voto 
del electorado transnacional, al mismo tiempo que la "presencia consular" colabora a la hora de habilitar votantes o ampliar las redes políticas. En campaña, entonces, las actividades consulares se intensifican y van acompañadas de decisiones altamente valoradas por los migrantes, como la reducción o la eliminación de los aranceles de ciertos trámites o el anuncio de la incorporación de nuevas funciones o "servicios”. A modo de ilustración, en uno de los actos de la campaña electoral del FAUA en el 2014, el entonces canciller —en ese momento candidato a senador por el FA - informó sobre la firma de acuerdos para que los cónsules pudieran expedir partidas de nacimiento y defunción. Con esta medida el candidato ejemplificaba un cambio en "la lógica de lo que eran los servicios consulares en Uruguay, los cuales generalmente estaban vistos como servicios diplomáticos de segunda categoría”, al mismo tiempo que exponía su labor ante la diáspora asistente, cuyo voto solicitó explícitamente: “todos los que están acá deben ir a votar [...] Porque no te puede dar igual, porque en este tiempo hemos construido un país con cada vez más derechos”.

Las territorializaciones de las políticas extraterritoriales que vimos hasta aquí también suman la presencia consular en el espacio público en fechas precisas, como el Día del Inmigrante celebrado en Buenos Aires en septiembre. Mediada por el Consulado, la participación del colectivo uruguayo no parece cobrar la trascendencia o relevancia que adquieren las fechas nacionales y desfiles en Nueva York. Por lo general, y a diferencia de lo que sucede con otras comunidades de migrantes en la capital argentina, el Consulado participa en estos eventos convocando a algunas asociaciones de migrantes, particularmente a aquellas que practican el candombe afrouruguayo (Parody 2016). Posiblemente esto se explique por las características atribuidas a la migración uruguaya en el país, mencionadas en el segundo acápite. Me refiero a aquella "integración de hecho" enfatizada por gran parte de mis interlocutores como una de las vías de distinción de lo que supone ser "migrante limítrofe”, una identificación fuertemente estigmatizada en Argentina (Merenson 2015a).

\section{Palabras finales}

Hasta aquí me propuse mapear los lugares en los que la acción estatal extraterritorial es practicada por funcionarios de los consulados de Uruguay en las ciudades de Nueva York y Buenos Aires, y mediada por los hombres y mujeres migrantes asentados en ellas. Con este objetivo, en cada caso referí las articulaciones 
entre las trayectorias migratorias, las trayectorias profesionales y los estilos consulares de sus funcionarios, y algunas de las políticas de los países de destino entendidas en un sentido amplio; es decir, no solo aquellas dirigidas a la población migrante, como los programas de asistencia social, las leyes tributarias y jubilatorias. Vale aclarar que esto último no quiere decir que las normativas migratorias vigentes en cada país de destino no operen como poderosos marcos de regulación de las acciones consulares, sino que estas no son las únicas explicaciones posibles.

A partir de las articulaciones mencionadas busqué explorar las diversas formas en que una serie de políticas estatales extraterritoriales definidas por un país (el de origen) se territorializan en dos países y ciudades de destino. Esto me permitió describir los modos en que la racionalidad instrumental atribuida a las burocracias estatales - en este caso, diaspóricas - no solo es parte de una activa y compleja negociación que incluye las necesidades y expectativas de distintos actores extraestatales, sino que implica el rediseño de las políticas de un Estado en el seno de otro a partir de saberes expertos, pero también del sentido común, los intereses personales y las emociones. Sobre todo ello opera, en distintas combinaciones posibles, la distancia estructural y la distancia simbólica a las que agentes consulares y migrantes aluden como “estar cerca” o “lejos” unos de otros.

Como puede derivarse del análisis etnográfico de cada caso, las burocracias diaspóricas y los migrantes no necesariamente perciben y codifican de forma análoga, es decir, no siempre comparten los criterios respecto de cuándo y cómo un determinado evento se transforma en un problema que requiere la intervención del Consulado, de los referentes de la comunidad migrante o de ambos. Aquí me propuse identificar en qué circunstancias y cómo se acomodan, en caso de hacerlo, los comportamientos de los actores a las matrices institucionales y los desplazamientos territoriales que ello supone. Estas cuestiones se revelan como claves para comprender que las oficinas consulares no solo no son un "mundo árido de papeles”, sino que en algunos casos actúan como activas promotoras de una comunidad que excede a la comunidad migrante.

Del recorrido propuesto hasta aquí también puede derivarse que, así como no existe una única forma de entender, encarnar y representar "el Estado" fuera de sus fronteras territoriales, tal como lo demuestran las palabras y las prácticas de Mónica, Laura y sus colaboradores, tampoco existe una única forma de demandar sus presencias, acompañar una gestión o criticarla. En este sentido, las diversas interacciones cara a cara - aquellas que generan los compromisos y las interpretaciones que producen un espacio como lugar- exponen formas específicas de evaluar a las delegaciones diplomáticas que, por lo 
general, escapan a las prácticas de control y enjuiciamiento de las democracias liberales (Rosanvallon 2006). En esta tarea, los límites entre la acción política y la estatal pueden resultar sutiles o incluso autonomizarse respecto de las trayectorias profesionales. Recordemos que, así como para "los compatriotas” Mónica puede transformarse en una "política” cuando "no se mueve” ante la deportación de una persona, pero espera que los migrantes asistan a los actos que organiza el Consulado, Laura puede ser considerada una "burócrata" cuando no contempla prácticas discrecionales con quienes sostiene vínculos políticos previos a su designación como cónsul.

Vimos también que las agendas de trabajo y los estilos consulares varían tanto como los mapas establecidos para cada jurisdicción, que siguen criterios de agregación y clasificación diferenciales, asociados a los procesos de incorporación urbana de los colectivos migrantes. Si bien tareas comunes como la emisión de documentos estatales, los procedimientos ante deportaciones y repatriaciones, la realización de consulados itinerantes o la organización de eventos en fechas rituales adquieren formas y sentidos diversos -incluso antagónicos-, ambos casos indican un profundo anclaje territorial tejido en el marco de arreglos locales, producto de los vínculos entablados con las comunidades migrantes, autoridades municipales, empresarios, políticos y otros cuerpos diplomáticos. Estos vínculos vienen a reforzar la importancia que Smith (2007), entre otros autores, le atribuye a la escala local en los procesos de construcción de ciudadanía transnacional, demostrando que las políticas estatales extraterritoriales son irreductiblemente territorializadas de modos tan diversos como aleatorios. Advertir lo mencionado hasta aquí, y entender sus lógicas divergentes, límites y potencialidades, fueron el objetivo de este artículo.

\section{Referencias}

Aldaba, Juan. 2017. “De andar lejos: la idea de ciudadanía transnacional y la política exterior de vinculación con los uruguayos en el exterior durante el primer gobierno del Frente Amplio”. Tesis de maestría, Facultad de Ciencias Sociales, Universidad de la República, Montevideo.

Basch, Linda, Nina Glick Schiller y Cristina Szanton Blanc. 1994. Nations Unbound: Transnational Projects, Postcolonial Predicaments and Deterritorialized Nation-States. Ámsterdam: Gordon \& Breach.

Bauböck, Rainer. 2003. “Towards a Political Theory of Migrant Transnationalism”. International Migration Review 3 (37): 700-723. https://doi.org/10.1111/j.1747-7379.2003.tb00155.x. 
Benencia, Roberto. 2007. “La migración limítrofe”. En Poblacióny bienestar en la Argentina del primero al segundo centenario, editado por Susana Torrado, 571-599. Buenos Aires: Edhasa.

Bertoncello, Rodolfo. 2001. "Migración, movilidad e integración: desplazamientos poblacionales entre el Área Metropolitana de Buenos Aires y Uruguay”. Scripta Nova. Revista Electrónica de Geografía y Ciencias Sociales 94 (71). Consultado el 14 de noviembre del 2017. http://www.ub.edu/geocrit/sn-94-71.htm.

Besserer, Federico y Daniela Oliver. 2014. Ensamblando la ciudad transnacional. Etnografía especular de los espacios transnacionales urbanos. Ciudad de México: JP-UAM-I.

Collyer, Michael y Russell King. 2014. "Producing Transnational Space: International Migration and the Extra-territorial Reach of State Power”. Progress in Human Geography 39 (2): 185-204. dx.doi.org/10.1177/0309132514521479.

Dickinson, Jen. 2015. "Articulating an Indian diaspora in South Africa: The Consulate General of India, Diaspora Associations and Practices of Collaboration”. Geoforum 61: 79-89. 10.1016 / j.geoforum.2015.02.014.

Espeche, Ximena. 2016. La paradoja uruguaya. Intelectuales, latinoamericanismo y nación a mediados del siglo XX. Bernal: Universidad Nacional de Quilmes.

Evans-Pritchard, Edward. 1977. Los nuer. Barcelona: Anagrama.

Faist, Thomas. 2004. "The Border Crossing Expansion of Social Space: Concepts, Questions and Topics”. En Transnational Social Spaces, editado por Thomas Faist, 1-34. Aldershot: Ashgate.

Featherstone, David, Richard Phillips y Johanna Waters. 2007. "Introduction: Spatialities of Transnational Networks”. Global Networks 7: 383-391. DOI: 10.1111 / j.1471-0374. 2007.00175.x.

Gilroy, Paul. 2014. The Black Atlantic: Modernity and Double Consciousness. Cambridge: Harvard University Press.

Goldring, Luin. 2004. "Family and Collective Remittances to Mexico". Development and Change 35 (4): 799-840. https://doi.org/10.1111/j.0012-155X.2004.00380.x.

Gupta, Akhil y James Ferguson. 2008. "Más allá de la cultura: espacio, identidad y políticas de la diferencia”. Antípoda 7: 233-256.

Hallet, Miranda y Beth Baker Cristales. 2010. "Diasporic Suffrage: Voting Rights in the Salvadoran Trans-nation”. Urban Anthropology 39 (1-2): 175-211.

Hannerz, Ulf. 1996. Transnational Connections: Culture, People, Places. Londres: Routledge.

Hull, Matthew. 2003. “The File: Agency, Authority, and Autography in an Islamabad Bureaucracy”. Language \& Communication 23: 287-314.

-. 2012. "Documents and Bureaucracy". Annual Review of Anthropology 41: 251-267.

Kishan, Rana. 2007. Bilateral Diplomacy. Ginebra; Malta: Diplo Handbooks.

Lafleur, Jean-Michel, ed. 2012. Diáspora y voto en el exterior. La participación política de los emigrantes bolivianos en las elecciones de su país de origen. Barcelona: Cidob. 
Laszczkowski, Mateusz y Madeleine Reeves, eds. 2015. Affective States. Entanglements, Suspensions, Suspicions. Nueva York; Oxford: Berghahn.

Marcus, George. 1995. "Ethnography in/of the Word System: The Emergence of Multisited Ethnography”. Annual Review of Anthropology 24: 94-117.

Merenson, Silvina. 2013. “Tras el voto Buquebus. Políticas, prácticas e interdependencias en la producción de la ciudadanía transnacional”. Desarrollo Económico 52 (207-208): 285-306.

-. 2015a. "Between Brotherhood and Exceptionalism: Processes of Identification, Social Marking, and Justification in Uruguayan Immigration in Buenos Aires”. Migraciones Internacionales 8 (1): 9-37.

—. 2015b. "Del 'exilio' a 'la diáspora'. Lenguajes y mediaciones en el proceso de diasporización uruguayo”. Horizontes Antropológicos 21 (43): 211-238.

—. 2016. "El voto extraterritorial en Uruguay. Inequidades y asimetrías en una trama política transnacional”. Revista de Investigaciones Políticas y Sociológicas 15 (1): 123-142.

Neumann, Iver. 2013. Diplomatic Sites: A Critical Enquiry. Nueva York: Columbia University Press.

Organización Internacional para las Migraciones. 2011. Perfil migratorio de Uruguay 2011. Buenos Aires: Oficina Regional para América del Sur.

Parody, Viviana. 2016. “Candombe afrouruguayo en Buenos Aires. Territorio, cultura y política (1974-2014)”. Tesis de maestría, Departamento de Antropología, Facultad Latinoamericana de Ciencias Sociales, Buenos Aires.

Pascucci, Elsa. 2016. “Transnational Disruptions: Materialities and Temporalities of Transnational Citizenship among Somali Refugees in Cairo”. Global Networks 16: 326-343. https://doi.org/10.1111/glob.12115.

Peirano, Marisa. 2002. “This Horrible Time of Papers': Documents and National Values”. Série Antropologica 312: 3-31.

Pries, Ludger. 1998. Migration and Transnational Social Spaces. Aldershot: Ashgate.

Recalde, Aranzazu, 2002. "Los inmigrantes de origen latinoamericano en la ciudad de La Plata”. En ¿Dónde están los inmigrantes? Mapeo sociocultural de los grupos de inmigrantes y sus descendientes en la provincia de Buenos Aires, editado por Martha Maffia, 179-207. La Plata: Al Margen.

Rodrigo, Federico. 2017. "La producción transnacional del Estado y la nación. La política consular boliviana y los procesos de constitución de la 'colectividad' en la ciudad de La Plata”. Tesis doctoral, Instituto de Desarrollo Económico y Social, Universidad Nacional General Sarmiento, Buenos Aires.

Rosanvallon, Pierre. 2006. La contre-démocratie. La politique à l'âge de la défiance. París: Editions du Seuil.

Smith, Michael. 2007. “The Two Faces of Transnational Citizenship”. Ethnic and Racial Studies 30 (6): 1096-1116. https://doi.org/10.1080/01419870701599523. 
Smith, Robert. 2008. "Contradictions of Diasporic Institutionalization in Mexican Politics: the 2006 Migrant Vote and other Forms of Inclusion and Control”. Ethnic and Racial Studies 31 (4): 708-741. https://doi.org/10.1080/01419870701599523. https://doi. org/10.1080/01419870701785528.

Trigo, Abril. 2003. Memorias migrantes. Testimonios y ensayos sobre la diáspora uruguaya. Rosario: Beatriz Viterbo.

Trouillot, Michel-Rolph. 2003. Transformaciones globales: la antropología y el mundo moderno. Cauca, Bogotá: Universidad del Cauca; CESO - Universidad de los Andes.

Turner, Victor. 1974. Dramas, Fields, and Metaphors. Ithaca: Cornell University Press. 